\title{
Spiritualism and Science Studies for the Twenty-First Century
}

\author{
Christine Ferguson | ORCID: 0000-0002-2261-6290 \\ University of Stirling, Sterling, Scotland, UK \\ Christine.ferguson@stir.ac.uk
}

Efram Sera-Shriar | ORCID: 0000-0003-3163-3487

Science Museum, London, UK

efram.sera-shriar@sciencemuseum.ac.uk

Science and spiritualism studies is an interdisciplinary academic sub-field of no recent vintage. Since the early nineteen-seventies, studies of major scientific naturalists such as Alfred Russel Wallace, Edward Burnett Tylor, William Crookes, and others have showed a growing willingness to acknowledge and account for the psychical interests and sometimes ardent spiritualist convictions of their subjects. From these initially individualistic case studies has emerged a broader picture of the role of spiritualist beliefs and psychical investigation on the settlement of modern scientific disciplines, methods, and networks. This trajectory is exemplified with particular clarity in the sub-titular ambition of Richard Noakes's excellent 2019 Physics and Psychics: The Occult and the Sciences in Modern Britain, a study which establishes psychical research not as the faddish interest of a cadre of admittedly high-placed scientific eccentrics, but rather as a key catalyst in the late-Victorian development of the physical sciences. At the start of the twentieth century, he argues, psychical research and spiritualist phenomena may have been frequently derided by physical scientists, but they were also far more difficult to ignore than they have since become. Even if only to be rejected and debunked, such subjects demanded address by leading scientific naturalists of their day.

The current special issue of Aries takes inspiration from and responds to this increasing complex historiography of spiritualism and science, noting its gains and addressing its challenges. Perhaps chief among the latter is the need to overcome a persistent lack of confidence about, or understatement of, the 
extent of its own scholarly settlement. The post-millennium surge of academic research on psychical research and scientific spiritualists should by now have firmly established a sense of historical interconnection, if by no means easy consilience, between science and spiritualism in the modern West. ${ }^{1}$ Major works by Roger Luckhurst, Corrina Treitel, John Warne Monroe, Mark Morrison, Egil Asprem and others have advanced us far beyond the time when, as Malcolm Jay Kottler observed in 1974, the psychical research pursuits of leading European scientists had 'been forgotten, ignored, or perhaps never known by historians of science.'2 Yet two recent major studies of science and spiritualism, published almost fifty years after Kottler made these remarks, open by insisting that this condition of scholarly ignorance remains largely unabated, and that 'scholars', in the words of Jason Josephson-Storm, 'would be surprised to learn that [Marie Curie] was conjuring ghosts or studying paranormal manifestations as part of her physics research. ${ }^{3}$ Would they really, in lights of the subject's ample historiographical gains? What is at stake in imagining or rhetorically soliciting this form of audience surprise, or even in the case of Courtney Raia's The New Prometheans (2019), rejection? In the latter, Raia urges researchers to 'tak[e] seriously', as if for the first time, the psychical research of figures like William Crookes and Oliver Lodge, and calls upon an unspecified 'we' to abandon the usual dismissal or derision with which such topics have been treated. ${ }^{4}$ Neither Raia's nor Josephson-Storm's compelling monographs are unaware of the decades of previous research on psychical research to which they contribute, but both seem uncertain as to the degree of its saturation and impact. Their hesitant framing positions spiritualism and science studies within a curious feedback loop, one in which advances in knowledge are coupled with skittish reassertions, even reinventions, of the topic's previous obscurity. The articles in this issue are united by a willingness to move beyond this hesitancy and to insist that the relevance of spiritualism to the history of science is no longer unknown nor in question. Their

1 See for example Luckhurst, The Invention of Telepathy, Lamont 'Spiritualism and a MidVictorian Crisis of Evidence', Treitel A Science for the Soul: Occultism and the Genesis of the German Modern, Morrison Modern Alchemy: Occultism and the Emergence of Atomic Theory, Monroe Laboratories of Faith: Mesmerism, Spiritism, and Occultism in Modern France, Asprem The Problem of Disenchantment: Scientific Naturalism and Esoteric Discourse, 190o1939, Josephson-Storm The Myth of Disenchantment: Magic, Modernity, and the Birth of the Human Sciences and Raia The New Prometheans: Faith, Science, and the Supernatural Mind.

2 Kottler, 'Alfred Russel Wallace, the Origin of Man, and Spiritualism', 145.

3 Josephson-Storm, The Myth of Disenchantment, 3.

4 Raia, The New Prometheans, 4. 
goal is not to originate, but to complicate and diversify, our understanding of the relationship between these two forms of practice and ontological production.

In embracing a more confident approach to the historiographical gains achieved over the last five decades of science and spiritualism studies, it is important not to lose sight of why such topics might continue to feel marginal despite their unprecedented scholarly recognition within the history of science, religious studies, esotericism studies, and cultural history. One reason might lie in the significant disparity between the reception of science and spiritualism studies within and beyond the academy. While it should no longer prove controversial to simply acknowledge the spiritualist convictions of Alfred Russel Wallace, Charles Richet, or Cesare Lombroso within a history of science context, the case is very different within the broader public sphere. In early 2017, one of this issue's editors participated in a panel discussion on the scientific career and legacy of British physicist Oliver Lodge at the Royal Institution in London. Speakers addressed a range of topics, including Lodge's pioneering role in the development of wireless telegraphy, advancement of ether theory, championship of public scientific education, and, ultimately, his advocacy of the survival hypothesis in the World War I spiritualist testimonial he dedicated to his lost son, Raymond, or Life After Death (1916). The mere mention of the latter topic alongside the former of Lodge's commitments was enough to send at least one audience member into a fury; in the question-and-answer session, he declared to the panel, 'Just behind you on the wall it's got "Royal Institution: Science Lives Here." I'm afraid that science died here tonight."5 His reaction evidences a persistent and perhaps understandable queasiness that often accompanies discussions of alternative or rejected forms of historical scientific investigation at a time when contemporary science research faces threat by both governmental funding cuts and dangerous forms of populist anti-scientific scepticism, such as anti-vaccinationism and climate change denial.

This special issue is based on the conviction that contemporary STEM research is robust enough to withstand an exploration of its heterodox history, one whose existence we neglect at our peril and whose recognition should in no way be conflated with endorsement or a desire for reinstatement. Nonetheless, it would be a mistake to trivialize the suspicion and even hostility which the investigation of such topics elicits within our increasingly post-secular society. Just as the next generation of researchers in this dynamic interdisci-

5 'Man Says: Science Died Here Tonight, at Royal Institution lecture on spirits'. 
plinary sub-field need no longer rhetorically re-marginalize psychical research or spiritualistically-affiliated scientists—no longer insist that each represents a virgin territory with little presence in historiography or popular culture-so too must they remain alert to the sensitivities and controversies which they continue to provoke.

The present special issue responds to these complex requirements through a set of six paired articles that assess and challenge previous historiographical developments within science and spiritualism studies, expanding them in the light of new methodological perspectives, cultural and geographical locations, forms of textual production, and historical actors. It shares with previous scholarship a focus on the nineteenth-century period in which modern spiritualism and psychical research were at their height, and on the European environment in which the latter currents exerted some of their most significant cultural effects. Yet they invoke these familiar contexts in order to re-orient them towards a widened range of disciplines and discursive histories. How, our contributors ask, did scientific entanglements with spiritualist belief and heterodox practice take place outside the laboratory and beyond the metropole? In what hitherto unconsidered locations - the vegetarian restaurant, for example, or the private men's club-did scientific entanglements with spiritualism take place, and how might their recognition expand our understanding of the cultural and social geographies of science? Through what figures has the history of psychical research traditionally been told, and how has that selectionelite male professionals and female or working-class male mediums-not only reflected, but in some cases reproduced, the gendered exclusions and skewed power dynamics of nascent nineteenth-century professional scientific establishments? Contributors also demonstrate how has the authority and reception of scientific investigations of spiritualism, both hostile or sympathetic, were conditioned by the print forms and the epistemological conventions they adopted, arguing, in the process, for a closer engagement between spiritualism and science studies and book history, periodical studies, and visual culture scholarship.

The articles are also connected by a shared interest in the status and role of judgement - critical, ontological, ethical—within the historical assessment of alternative scientific practices and heterodox belief. As Roger Luckhurst observes later in this issue, the first wave of academic scholarship on spiritualism and science was dominated by a Whiggish, apologetic impulse to explain why particular scientific elites had embraced allegedly fantastical or anti-rational beliefs that the academy had since safely rejected; the second wave, by contrast, sidestepped or ignored debates about the veracity of reported psychical phenomena in order to focus instead on their historical sig- 
nificance for the formation of scientific knowledge and professional authority. Such a position of agnostic neutrality has usefully enabled the study of histories and subjects once considered unfit for scholarly investigation or funding; as editors, our own research careers would have been impossible without it. But it is a position that requires continual reassessment and adjustment. Is suspending judgment in this context always the right thing to do? Consider, for example, the ardent anti-vaccinationism that Anna Kingsford and other late-Victorian spiritualist believers worked to promote; what would have been the consequences of its mass adoption? While the fact that Kingsford was demonstrably and disastrously wrong about Pasteur's experimental results on the rabies vaccine need not be the only thing to say about her, surely it must be at least one of them. Even if any attempt to validate or falsify the phenomenal claims made by historical spiritualist believers must ultimately prove futile, we can and must scrutinize the forms of authority and political assumptions through which they staked them. In doing so, we stand to gain a richer understanding of the social consequences, hierarchical effects, and ethical implications of historically-situated forms of scientific spiritualism and anti-supernaturalism alike. Spiritualism and the Sciences: An Introduction to the Case Studies

Far too often the history of Victorian spiritualism and its interactions with the sciences is told through the shared experience of a small group of actors, usually typified by a naturalist investigating a medium's professed powers. In these narratives, figures such as William Crookes and Daniel Dunglas Home, or Alfred Russell Wallace and Agnes Elisabeth Guppy tend to dominate the headlines. However, by only following the history of science and spiritualism through the narrow gaze of these well-known stories, its past remains obscured. To fully appreciate the diverse experiences of Victorians and their relationship to science and spiritualism, it is important to push beyond the conventional narrative and explore its "multiple contextualisations;" that is, the distinct circumstances under which these historical actors engaged, interpreted, responded to, and even rejected spiritualism's and science's multi-layered manifestations. ${ }^{6}$ There was no singular experience with these cultural phenomena, and it is

6 We are borrowing the term 'multiple contextualizations' from George Stocking's pioneering essay, 'Retrospective Prescriptive Reflections.' See Stocking, The Ethnographer's Magic, 3-4. 
only by studying different perspectives together that we can approach a more wholistic understanding of Victorian spiritualism and its relationship to the sciences.

In this collection of papers, we explore some of these contexts as a way of enriching our understanding of the history of science and spiritualism in the Victorian age. For instance, by coupling the more conventional storyline with lesser-known case studies, a more complex historical picture emerges. It is for this reason that we open the collection with a pair of articles that examine the spirit investigations of the scientific naturalists John Tyndall and William Crookes respectively. They both represent useful reference points for juxtaposing the traditional narratives with newer interpretations. What is more, these two articles offer a useful route for exploring our first major theme, "knowledge production."

For several decades now, historians of science have been interested in the modes of production historical actors used to create scientific knowledge. Steven Shapin and Simon Schaffer's ground-breaking work, Leviathan and the Air Pump (1985), was, in many ways, transformative for these kinds of studies. Their concept of "virtual witnessing," in particular, with its emphasis on collective testimony, replication, and virtual recreation through text, were key to unlocking how historical actors constructed rational understandings of the world around them, and the social processes through which historical actors made claims about intellectual expertise and skilled practice. ${ }^{7}$ Other scholars have since added further to this historiographical discussion. For example, more recently, James Elwick in his Styles of Reasoning in the British Life Sciences (2007) showed how naturalists such as Thomas Henry Huxley developed specialized strategies (both professional and personal) to forward particular visions of biology within British scientific circles. By closely unpacking the "styles of reasoning" these naturalists employed, we see how researchers in the Victorian period utilized a range of techniques for producing new ways of understanding the organic world. ${ }^{8}$ Loraine Daston and Peter Galison's now famous book, Objectivity (2007), was equally important for transforming scholarly understandings of scientific knowledge production. In their case, they traced the modern construction of "objectivity" in the sciences through various epistemic frameworks, including visual, social, and naturalistic models. ${ }^{9}$

In the opening article of this collection, Ian Hesketh, builds on the historiographical theme of knowledge production by exploring how William Crookes

7 Shapin and Schaffer, Leviathan and the Air-Pump, 55-65.

8 Elwick, Styles of Reasoning.

9 Daston and Galison, Objectivity. 
used his editorship of the Quarterly Journal of Science to forward the scientific importance of spirit phenomena to a broad readership. Key to this examination is a consideration of Crookes' publishing strategy. Rather than sharing his final results in a single article, Crookes chose to publish his investigations into spirits and psychic forces as a series of entries over a four-year period. In doing so, Crookes was able to adapt his experiments in response to the feedback and criticisms he was receiving in the media. Thus, Crookes' knowledge production was tightly connected to the form and presentation of his research program as portrayed in the periodical press.

In the second paper, Efram Sera-Shriar throws fresh light on John Tyndall's investigation of spiritualism by examining the visual epistemologies he used to challenge the legitimacy of the spirit hypothesis. By exploring this interplay, Sera-Shriar argues that it is possible to understand the politics of construction used by naturalists to corroborate the credibility of their testimonies. Moreover, through this examination of Tyndall's engagement with spiritualism, the paper also challenges earlier whiggish accounts in the secondary literature that have maintained the myth that scientific naturalism conquered spiritualism during the nineteenth century. By revealing a more complex narrative, Sera-Shriar's examination of Tyndall's participation in spirit investigations underlines the uneasy relationship Victorian science had with spirit and psychic forces, and raises important questions about the authority and limit of scientific naturalism in the process. An interrogation of Victorian knowledge production is therefore at the root of this case study.

The second theme of this special issue is "networks." Over the past decade and a half, historians have increasingly considered the role of network theories in redefining our understanding of the Victorian period. Within the history of science, two frameworks in particular have taken centre stage: Bruno Latour's "actor-network theory," and James Secord's "knowledge in transit" model. In both cases, these scholars argue that to fully appreciate how knowledge is formed, you must consider the roles different kinds of historical actors played in shaping it. No researcher works in isolation, and according to both Secord and Latour, all forms of knowledge are "social acts." Thus, by tracing the different players involved in producing these knowledge networks, we can come to understand the making of the modern world as a multi-directional traffic of ideas, practices, and experiences. ${ }^{10}$ While "networks" are important themes in both Luckhurst's and McCorristine's articles, so too is the issue of "location." Cultural geography and the dynamics of space have been increasingly impor- 
tant to the history of science as a result of ground-breaking studies such as David Livingstone's Putting Science in its Place (2003), which in many respects established the fundamental importance of geography in both the production and consumption of scientific knowledge. ${ }^{11}$

Actor networks and spatial location are core to the third paper of this collection by Roger Luckhurst on the formation and early years of the Ghost Club, a spiritualist group led by William Stainton Moses and Alfred Alaric Watts. A London-based collective ruled by a supposed gentleman's code of honour, its activities and discussions were strictly confidential. Nevertheless, despite maintaining a heightened level of secrecy, members of the Ghost Club kept meticulous records of their meetings and transactions, leaving behind a comprehensive archive. Luckhurst explores these materials as a way of readjusting our scholarly understanding of the kinds of spiritualist and occultic networks that were active in late Victorian and early Edwardian London. Thus, the geography of the Ghost Club's network comes to the fore.

In the fourth paper of the collection, Shane McCorristine examines William Fletcher Barrett's dual interests in physics and psychics. McCorristine aims to re-evaluate Barrett's career by focusing on his networks, projects and organisational participation in Ireland. As McCorristine argues, these three aspects of Barrett' professional life acted as a bridge, connecting his work as a teacher of physics at the Royal College of Science for Ireland with his work on psychical research and spiritualism. While much has been written on the history of science and spiritualism from a British perspective, considerably less has been done on the Irish context. Thus, the article also contributes to the history of science and spiritualism by demonstrating the rich connections that existed in Ireland between naturalists, intellectuals, and amateur investigators interested in these subjects. Furthermore, we see a wonderful demonstration of the importance of geographical place in shaping scientific knowledge.

The final two articles in our issue turn their focus to the role of embodiment and corporeality in scientific explorations of the numinous, building on, extending, and challenging the previous work on this topic conducted under the aegis of the feminist historiography of mediumship. First brought to the fore in discussions of Victorian spiritualism in the 1980 s by the groundbreaking book of Alex Owen, The Darkened Room (1989) and the formative article by Judith Walkowitz's 'Science and the Séance' (1988), there has been a growth of literature that has explored the intersection of bodies, gender, sci- 
ence, and spiritualism over the past few decades. ${ }^{12}$ Notable examples include the works of Marlene Tromp, Jill Galvan, and Elizabeth Schleber Lowry. ${ }^{13}$ These scholars have done much to reconsider the social, aesthetic, and political dimensions of the spiritualist movement. The history of Victorian science has also explored the interrelationship between science, gender, and bodies more broadly, including key works such as Ann Shteir and Bernard Lightman's Figuring It Out (2006), and Heather Ellis' Masculinity and Science in Britain (2017).14

Drawing on these themes, in the fifth paper of this collection, Christine Ferguson examines the life of Anna Kingsford, an occultist, anti-vivisectionist, and physician. As Ferguson rightly argues, Kingsford is absent from most studies of Victorian science and spiritualism, and yet her efforts to bring together occultic and scientific paradigms is significant. To a certain degree, her erasure from the historiography has much to do with the propensity by scholars to over fixate on the canonical stories of male figures such as Wallace and Crookes, while ignoring the stories of their female Victorian counterparts. By decentring these well-known narratives through a critical reassessment of the gendered politics of writing, that are rampant within the secondary literature, Ferguson positions Kingsford as a key historical actor at the intersection of science and spiritualism in the late Victorian era. Moreover, by exposing the tensions and complexities in Kingsford's writings, Ferguson also aims to redress gaps in recent esotericism studies that have engaged the so-called "disenchantment debate."15

In the sixth and final paper of the collection by Elsa Richardson, the theme of "bodies" comes full-circle through an examination of the relationship between Victorian spiritualism and nutrition. As Richardson shows in her innovative study, food and diet were a central part of the modern spiritualist movement's ethos. Spiritualist beliefs surrounding the purity of food, and more specifically vegetarianism, were core to the culture, and yet there has been little attention given to these issues in the historiography. Richardson's paper begins to address this gap by exploring the interrelation between body, diet, and spirit, demonstrating how the language of dietetics and the science of nutrition functioned in the séance room. Through this new interpretive approach to the study of Victorian science and spiritualism, Richardson reveals the complex, and often challenging, negotiation between immateriality and corporality in spiritualist, and to a larger extent occultic, discourse.

\footnotetext{
12 Owen, The Darkened Room and Walkowitz, 'Science and the Séance', 3-29.

13 See Tromp, Altered States, Galvan, The Sympathetic Medium, and Schleber Lowry, Invisible Hosts.

14 Shteir and Lightman, Figuring it Out and Ellis, Masculinity and Science in Britain.

15 For good overview of this debate see Josephson-Storm, The Myth of Disenchantment, 1-21.
} 
Our chosen cluster foci-knowledge production, networks and geographies, and bodies - represent just some of the ways in which the rich histories of spiritualism and the sciences intersect. We hope that the articles gathered here will render new ones visible, deepening the ongoing scholarly conversation on the complex relationship between orthodox and alternative forms of belief, and cementing a place for spiritualism and science scholarship at the heart of esotericism studies and the history of science.

\section{Bibliography}

Asprem, Egil, The Problem of Disenchantment: Scientific Naturalism and Esoteric Discourse, 1900-1939, Amsterdam: Brill 2014.

Daston, Lorraine, and Galison, Peter, Objectivity, New York: Zone Books 2007.

Ellis, Heather, Masculinity and Science in Britain, 1831-1918, London: Palgrave Macmillian 2017.

Elwick, James. Styles of Reasoning in the British Life Sciences: Shared Assumptions, $1820-$ 1858, London: Pickering \& Chatto 2007.

Galvan, Jill, The Sympathetic Medium: Feminine Channeling, the Occult and Communication Techologies 1859-1919, Ithaca: Cornell University Press 2010.

Lamont, Peter, 'Spiritualism and a Mid-Victorian Crisis of Evidence', The Historical Journal, 47 (2004), 897-920.

Livingstone, David N., Putting Science in its Place: Geographies of Scientific Knowledge, Chicago: University of Chicago Press 2003.

Josephson-Storm, Jason, The Myth of Disenchantment: Magic, Modernity, and the Birth of the Human Sciences, Chicago: University of Chicago Press 2017.

Kottler, Malcolm Jay, 'Alfred Russel Wallace, the Origin of Man, and Spiritualism', Isis 65.2 (June 1974), 145-192.

Latour, Bruno, Reassembling the Social: An Introduction to Actor-Network-Theory, Oxford: Oxford University Press 2007.

'Man Says: Science Died Here Tonight, at Royal Institution lecture on spirits', https:// www.youtube.com/watch?v=SB9O74VN7-k.

Monroe, John Warne, Laboratories of Faith; Mesmerism, Spiritism, and Occultism in Modern France, Ithaca: Cornell University Press 2008.

Morrison, Mark S., Modern Alchemy: Occultism and the Emergence of Atomic Theory, Oxford: Oxford University Press 2007.

Noakes, Richard, Physics and Psychics: The Occult and the Sciences in Modern Britain, Cambridge: Cambridge University Press 2019 .

Owen, Alex, The Darkened Room: Women, Power and Spiritualism in Late Victorian England, London: Virago Press 1989. 
Raia, Courtenay, The New Prometheans: Faith, Science, and the Supernatural Mind, Chicago: University of Chicago Press 2019.

Schleber Lowry, Elizabeth, Invisible Hosts: Performing the Nineteenth-Century Spirit Medium's Autobiography, Albany: State University of New York Press 2017.

Secord, James, 'Knowledge in Transit', Isis 95 (2004), 654-672.

Shapin, Steven, and Schaffer, Simon, Leviathan and the Air-Pump: Hobbes, Boyle, and the Experimental Life, Princeton: Princeton University Press 1985.

Stocking, George, The Ethnographer's Magic and Other Essays in the History of Anthropology, Madison: University of Wisconsin Press 1992.

Shteir, Ann B., and Lightman, Bernard (eds.), Figuring It Out: Science, Gender, and Visual Culture, Lebanon, NH: Dartmouth College Press 2006.

Treitel, Corinna, A Science for the Soul: Occultism and the Genesis of the German Modern, Baltimore: Johns Hopkins University Press 2004.

Tromp Marlene, Altered States: Sex, Nation, Drugs and Self-Transformation in Victorian Spiritualism, Albany: State University of New York Press 2007.

Walkowitz, Judith, 'Science and the Séance:Transgressions of Gender and Genre in Late Victorian London', Representations 22 (1988), 3-29. 